\title{
Roles of metals in human health
}

\begin{abstract}
This small review gives a glimpse as to how metals play crucial roles in our life. Their absence may lead several diseases in human body and several enzymes require them for their catalytic action. They have also been exploited to design drugs to treat several diseases like cancer, arthritis, and ulcer.
\end{abstract}

Keywords: metals, metal complexes, metal-containing drugs, metal-containing enzymes
Volume 2 Issue 5 - 2018

\section{Satya P Gupta}

Department of Pharmaceutical Technology, Meerut Institute of Engineering and Technology, India

\section{Correspondence: Satya P Gupta, Department of}

Pharmaceutical Technology, Meerut Institute of Engineering and Technology, Meerut-250005, India, Tel +9188 89534745 ,

Emailspgbits@gmail.com

Received: August 07, 2018| Published: September 19, 2018

\section{Introduction}

Metal ions are required to keep the human body healthy because several critical biological functions in humans depend upon their presence, and their absence or scarcity may lead to diseases. However, a few metal ions, particularly the so called heavy metal ions, such as mercury and lead, can be dangerous due to their toxic effects. Essential metal ions can also be toxic if present in excess, but their presence is crucial for survival. Among the metals that are currently known to be essential for normal biological functions in humans are sodium $(\mathrm{Na})$, potassium $(\mathrm{K})$, magnesium $(\mathrm{Mg})$, and calcium $(\mathrm{Ca})$ that belong to main group of elements, and vanadium $(\mathrm{V})$, chromium $(\mathrm{Cr})$, manganese $(\mathrm{Mn})$, iron $(\mathrm{Fe})$, cobalt $(\mathrm{Co})$, nickel $(\mathrm{Ni})$, copper $(\mathrm{Cu})$, zinc $(\mathrm{Zn})$, molybdenum (Mo), and cadmium (Cd) that belong to transition metal group of elements in periodic table. Among these metals, the most notable that usually exist in the form of ions, are $\mathrm{Fe}, \mathrm{Co}, \mathrm{Ni}, \mathrm{Ca}$, $\mathrm{Cu}, \mathrm{Zn}$, and $\mathrm{Cr}$. The deficiency of $\mathrm{Fe}$ and $\mathrm{Co}$ leads to anemia, that of $\mathrm{Cu}$ leads to brain and heart diseases and anemia, that of $\mathrm{Zn}$ leads to growth retardation and skin changes, that of $\mathrm{Ca}$ leads to bone deterioration, and that of $\mathrm{Cr}$ reduces the glucose tolerance. ${ }^{1-5}$ Thus, now-a-days, the important aspect of medicinal bioinorganic chemistry is related to study at the molecular level the diseases caused by the deficiency or excess of the various metal ions and to find their remedy. The most important aspect of metal ions is their use in drug discovery. The drug industry has not relied only on essential metal ions but also on other metals. Two most important drugs, cisplatin (1) and auranofin (2), are widely used for the treatment of genitourinary and head and neck tumors, respectively. Metals ions also play essential roles in a variety of enzymes and control enzyme-catalyzed reactions by modifying electron flow in substrates or enzymes. ${ }^{6}$ Without appropriate metal ion, a biochemical reaction catalyzed by a particular metalloenzyme may proceed very slow. Metals can serve to bind and orient substrate with respect to functional groups in the active site. Now we present here in brief some description of drugs that contain metals and also the enzymes that essentially require metals.

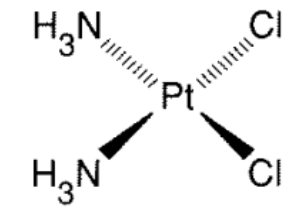

1,Cisplatinor cis-DDP Cis-diamminedicchloroplatinum(II)

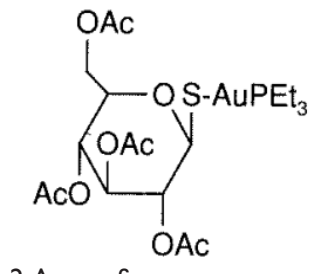

2, Auranofin

2,3,4,5-tetra-O-acetyl- I- I- $\beta$-Dthioglucose

(triethylphosphine)gold(I)

\section{Metal containing therapeutic agents}

\section{Platinum complexes}

In addition to cisplatin (1), there are several drugs that are complexed with platinum. Cisplatin is used to treat germ-cell cancers, gestational trophoblastic tumors, epithelial ovarian cancer, and small cell lung cancer as well as for the palliation of bladder, cervical, nasopharyngeal, esophageal, and head and neck cancers. ${ }^{7-9}$ However, some cancers were found to be resistant to cisplatin, ${ }^{10-11}$ and additionally several side effects were found to be associated with it. Consequently, another compound, carboplatin (3), was developed which had slightly low toxicity but its effectiveness to cancer was not much superior to cisplatin. In fact, for some tumors cisplatin was still to be therapeutically more effective than carboplatin. Further attempt to reduce the toxicity and drug resistance led to develop a new drug oxaliplatin (4) which was finally granted approval for use in the US in August 2002 for colorectal cancer in combination with 5-fluorouracil (5-FU). ${ }^{12,13}$ It had been earlier used in Europe for a number of years. Satraplatin (5, JM216), another platinum-based antineoplastic agent, is under investigation for the treatment of advanced prostate cancer, but it has not yet received approval from the U.S. Food and Drug Administration. However, despite the reputed inertness of Pt (IV) compounds, satraplatin undergoes rapid biotransformation in human red blood cells. ${ }^{14}$ Satraplatin is a direct analog of cisplatin (1). All direct structural analogs of cisplatin produce a very similar array of adducts on target DNA and thus they all induce similar biological consequences and may have a spectrum of clinical activity genuinely complementary to the parent drug even though structurally dissimilar. ${ }^{15-18}$<smiles>N[P+]1(N)OC(=O)C2(CCC2)C(=O)O1</smiles>

3, Carboplatin 4, Oxaliplatin 5, Satraplatin (JM-2I6)

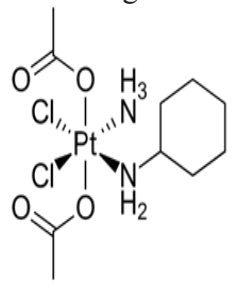

\section{Titanium complexes}

Two titanium complexes that have been found to act as anticancer agents are titanocene (6, MTK4) and budotitane (7, INN). Titanocene had shown the anticancer activity and was the first non-platinum complex to undergo clinical trials as chemotherapeutic drug..$^{19}$ Among non-platinum complexes, budotitane (INN), is among the most advanced ones. It is undergoing clinical trials today. Budotitane is 
highly active in several transplantable tumors and shows promising effects in an autochthonous colorectal tumor model, which is highly predictive for the clinical situation. ${ }^{20}$
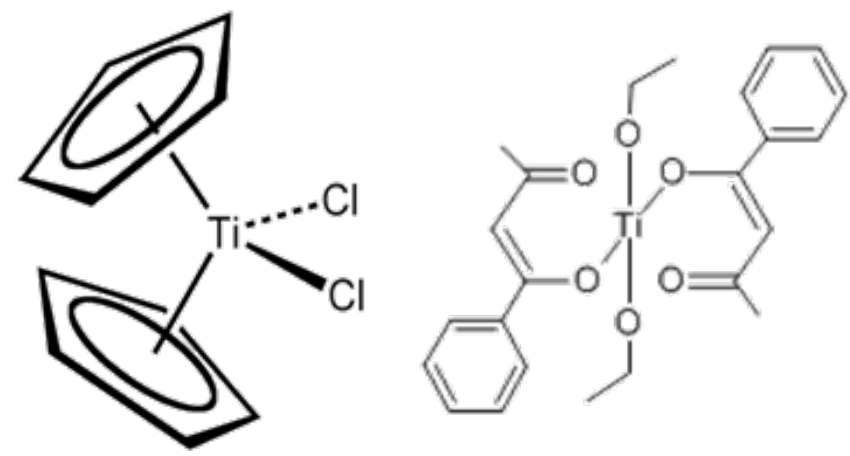

6,Titanocene (MTK4) 7, Budotitane (INN)

\section{Ruthenium complexes}

Ruthenium has produced compounds with the greatest promise, although no direct analogs have yet advanced to the clinic. NAMI-A (8) and KP1019 (9) are two ruthenium anticancer agents that have entered clinical trials. ${ }^{21,22}$ While NAMI-A is active against lung metastasis in vivo and tumor cell invasion in vitro, ${ }^{23-25} \mathrm{KP} 1019$ is useful for metastatic tumors and cis-platin resistant tumors. It exhibits potent cytotoxicity against primary tumors, particularly in colorectal cancer. ${ }^{26}$
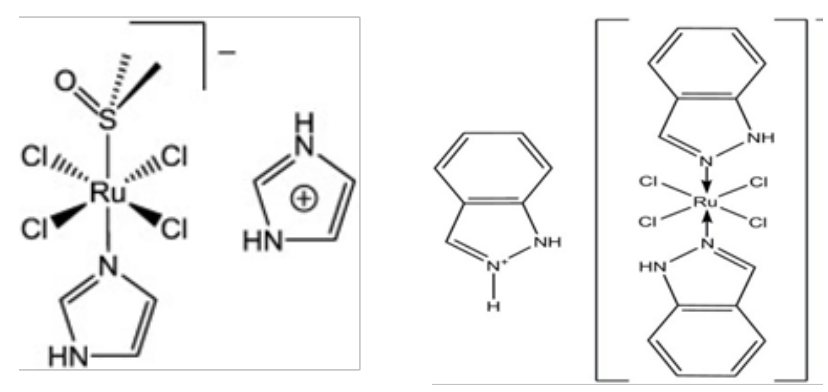

8, NAMI-A 9, KPIOI9

\section{Bismuth complexes}

Some bismuth-containing compounds have been used for their antacid and astringent properties in a variety of gastrointestinal disorders. ${ }^{27,28}$ An important compound, bismuth subsalicylate (10, Pepto-Bismol), is an antacid medication used to treat temporary discomforts of the stomach and gastrointestinal tract, such as diarrhea, indigestion, heartburn and nausea. A few more compounds are under development.

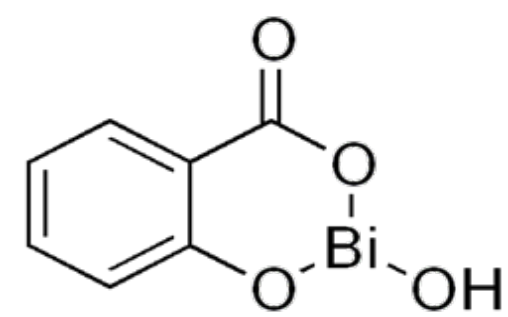

0, Pepto-Bismol

\section{Gold complexes}

Two gold complexes auranofin (11) and aurothioglucose (12), also known as gold thioglucose, were developed to treat rheumatoid arthritis. Auranofin improves arthritis symptoms including painful or tender and swollen joints and morning stiffness. ${ }^{29}$ Aurothioglucose was also developed to treat rheumatoid arthritis and it had been in use for more than 70years, ${ }^{30}$ but it was recently discontinued from the US market along with another gold complexes developed to treat rheumatoid arthritis leaving only auranofin as the only gold salt on the US market.
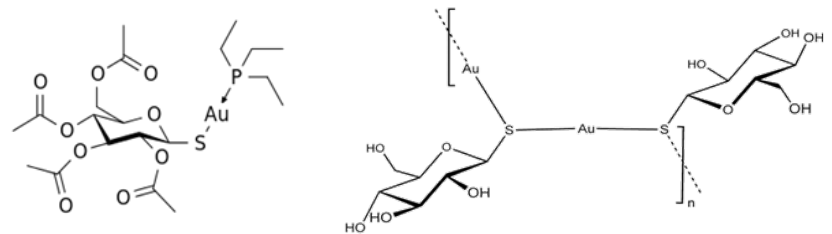

\section{II,Auranofin 12,Aurothioglucose}

\section{Role of metals in enzymes}

There are a large number of enzymes that contain metals and such enzymes are known as metalloenzymes. In all metalloenzymes, the metal ion is bound to the protein with one labile coordination site, and the metal ion is usually located in a pocket whose shape fits the substrate. The shape of the active site in all enzymes is crucial. In all metalloenzymes, the metal ion catalyzes reactions that are difficult to achieve in organic chemistry. These metalloenzymes are carbonic anhydrase, Vitamin B12-dependent enzymes, nitrogenase, superoxide dismutase, chlorophyll-containing proteins, hydrogenases, ribozyme and deoxyribozyme, and matrix metalloproteinases. Additionally, about half of all proteins contain a metal ${ }^{31}$ which are required to carry out their functions. ${ }^{32}$

In enzymes, metal ions are generally positively charged and act as electrophiles and thus enter into charge-charge interaction with any nucleophile. Groups or atoms that bind to the metal ions are negatively charged or neutral and thus donate electron density to the metal ions. The proper binding of the substrate in the binding site of the enzyme is greatly helped by electrostatic environment in the active site and the metal ions play a greater role here and facilitate action of enzyme. Metal ions facilitate the formation of transition state of the reaction to be catalyzed and ease out the release of the product. In many enzyme systems, a metal ion interacts with the oxygen of a water molecule. If a water molecule dissociates into an $\mathrm{H}^{+}$and $\mathrm{OH}^{-}$ ions, the $\mathrm{OH}^{-}$serves as a nucleophile in chemical or biochemical reactions. Such a nucleophile is obtained by the activation of water molecule in situ and thus a chemical reaction occurs in a stereo chemically controlled manner in the active site of the enzyme. In their catalytic functions, metalloenzymes use one of a few possible threedimensional arrangements of functional groups around the metal ion to ensure the specificity of the required biochemical reaction. ${ }^{33}$ In the crystal structures of many metalloenzymes, the preferred configuration has been found to consist of a carboxyl group in which one oxygen atom is bound to the metal ion and the other is bound to metal-bound water to give a cyclic structure. ${ }^{34-37}$ There are many enzymes such as hemerythrin, alkaline phosphatase and superoxide dismutases that have two metal ions in their active site. 
In the amide bond hydrolysis by metalloproteinases that contain zinc in the form of $\mathrm{Zn}^{2+}$, the $\mathrm{Zn}^{2+}$ is generally coordinated to three donor groups from the enzyme and a water molecule acquiring a tetrahedral geometry ${ }^{38}$ and the hydrolysis occurs as exemplified in Figure 1 for matrix metalloproteinases (MMPs), a major class of zinc-containing metalloproteinases. The donor groups from the enzyme may be the residues His $(\mathrm{N})$, Glu $(\mathrm{O})$, Asp $(\mathrm{O})$, or Cys $(\mathrm{S})$, where His is the most common. In the example for an MMP, Figure 1A shows that a water molecule while bonded to $\mathrm{Zn}^{2+}$ is also bonded to the carboxylate side chain of a glutamic acid residue. The $\mathrm{Zn}^{2+}$ ion is also coordinated to three histidine residues, His-228, His-222, and His-218. Bonding of water molecule to glutamic acid activates the water molecule for nucleophilic attack on the scissile amide bond that leads to transfer the proton $\left(\mathrm{H}^{+}\right)$to amide nitrogen and the carboxylate oxygen to be attached to $\mathrm{Zn}^{2+}$ in a tetrahedral manner (Figure 1B). Simultaneously, the transfer of a proton from the glutamic acid to the amide nitrogen also occurs followed by the collapse of the tetrahedral intermediate with the generation of a salt bridge between glutamic acid and free amine of the cleaved substrate (Figure 1C). It collapses via acid-mediated catalysis to products.

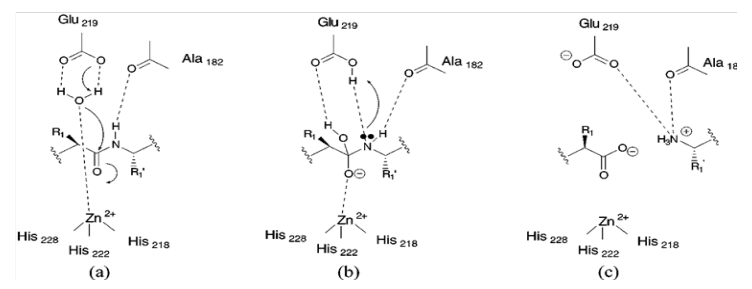

Figure I Catalytic mechanism for MMPs.

a. The catalytic water molecule is hydrogen-bonded to the zinc atom and the carboxylate side chain of a glutamic acid residue and is therefore activated for nucleophilic attack

b. Coordination of the carbonyl carbon of the amide bond is followed by nucleophilic attack of the zinc-bound water to give the tetrahedral intermediate

c. Which collapses via acid-mediated catalysis to products? Reprinted with permission from ref 38. Copyright 2000 American Chemical Society.

Figure 2 shows how an inhibitor can bind with zinc-containing enzymes. It shows an X-ray study as to how an N-carboxyalkyl peptide inhibitor binds with an MMP, stromelysin (MMP-3). ${ }^{38}$ The figure shows how, in addition to several hydrogen bindings; zinc atom stabilizes the binding of the inhibitor with the enzyme. The role of zinc atom has been presented in detail in review by Gupta. ${ }^{39}$ In fact, of all the metals, zinc has been found to perform a variety of functions in biological systems and it is because of its following properties as pointed out by Perkin ${ }^{40}$

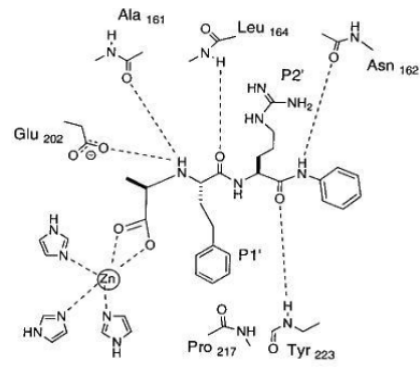

Figure 2 Binding of an MMP inhibitor with stromelysin (MMP-3) showing how the $\mathrm{Zn}$ atom participates in the bonding. In the figure $\mathrm{PI}$ and $\mathrm{P} 2$ refer to the groups of the inhibitor or substrate that bind to the corresponding binding sites referred to by $\mathrm{SI}^{\prime}$ and $\mathrm{S} 2$ in the enzyme. Reprinted with permission from ref 38. Copyright 2000 American Chemical Society.

i. Zinc is an element of borderline hardness ${ }^{41}$ and thus nitrogen, oxygen, and sulfur ligands interact favorably, leading its strong binding to proteins.

ii. The divalent zinc ion is exceptionally stable with respect to oxidation and reduction, and thus it does not participate in redox reactions.

iii. Zinc shows a strong preference in the enzymes for a tetrahedral coordination over an octahedral one, thereby enhancing both the Lewis acidity of the zinc center and the Brønsted acidity of a coordinated water molecule.

iv. As a result of $\mathrm{d} 10$ configuration of $\mathrm{Zn}^{2+}$, zinc complexes are not subject to ligand field stabilization effects, and so coordination number and geometry are only dictated by ligand size and charge.

v. Anions such as OH-, OR-, and SR- retain their nucleophilic character when coordinated to zinc. Only $\mathrm{Mn}^{2+}, \mathrm{Fe}^{3+}$, and $\mathrm{Cu}^{2+}$ are better in this regard.

\section{Conclusion}

Metals play very important roles in human life. Their absence may lead to several diseases in human body. Metals have also been exploited to design therapeutically useful drugs against several diseases like cancer, arthritis, ulcer, etc. Metals present in enzymes strongly facilitate their catalytic reaction.

\section{Acknowledgements}

None.

\section{Conflict of interest}

Author declares that there is no conflict of interest.

\section{References}

1. Metal Ions in Biological Systems. In: Seiler HG, Sigel H, Sigel A, editors. 14:1982.

2. Holm RH, Pierre Kennepohl P, Solomon EI. Structural and Functional Aspects of Metal Sites in Biology. Chem Rev. 1996;96(7):2239-2314.

3. Lippard SJ, Berg JM. Principles of Bioinorganic Chemistry. Mill Valley: University Science Books; 1994.

4. Cowan JA. Inorganic Biochemistry/An introduction. New Jersey: Wiley-VCH Inc;1994.

5. Tietz Textbook of Clinical Chemistry. 2nd ed. In: Carl A, Burtis CA, et al, editors. Saunders: Philadelphia; 1994.

6. De Silva JJRF, Williams RJP. The Biological Chemistry of the Elements. Clarendon Press: Oxford; 1991.

7. Weiss RB, Christian MC. New Cisplatin Analogues in development. A review. Drugs. 1993;46(3):360-377.

8. Lebwohl D, Canetta R. Clinical Development of Platinum Complexes in Cancer Therapy: an historical perspective and an update. Eur $J$ Cancer. 1998;34(10):1522-1534.

9. O'Dwyer PJ, Johnson SW, Hamilton TC. Cisplatin and its Analogues. In Cancer Principles and Practice of Oncology. 5th ed. In: DeVita VT, Hellman S, Rosenberg SA, editors. Lippincott-Raven: Philadelphia; 1997. 418-431 p. 
10. O'Dwyer PJ, Stevenson JP, Johnson SW. Clinical Status of Cisplatin, Carboplatin, and Other Platinum-based Antitumor Drugs. In Cisplatin Chemistry and Biochemistry of a Leading Anticancer Drug. In: Lippert B editor. Wiley-VCH: New York; 1999. 31-72 p.

11. Highley MS, Calvert AH. Clinical Experience with Cisplatin and Carboplatin. In: Kelland LR, Farrell NP, editors. Platinum-Based Drugs in Cancer Therapy. Cancer Drug Discovery and Development. New Jersey: Humana Press; 2000. 89-113 p.

12. Macdonald JS, Astrow AB. Adjuvant Therapy of Colon Cancer. Semin Oncol. 2001;28(1):30-40.

13. Pelley RJ. Oxaliplatin: a new agent for colorectal cancer. Curr Oncol Rep. 2001;3(2):147-155.

14. Carr JL, Tingle MD, McKeage MJ. Rapid biotransformation of satraplatin by human red blood cells in vitro. Cancer Chemother Pharmacol. 2002;50(1):9-15.

15. Farrell N, Qu Y, Hacker MP. Cytotoxicity and Antitumor Activity of Bis(Platinum) Complexes. A Novel Class of Platinum Complexes Active in Cell Lines Resistant to Both Cisplatin and 1,2-Diaminocyclohexane Complexes. J Med Chem. 1990;33(8):2179-2184.

16. Farrell N. DNA Binding and Chemistry of Dinuclear Platinum Complexes. Comm Inorg Chem. 1995;16(6):373-389.

17. Farrell N. DNA Binding of Dinuclear Platinum Complexes. In Advances in DNA Sequence Specific Agents. In: Hurley LH, Chaires JB, editors. Bingley: JAI Press. 1996;2:187-216.

18. Farrell N. Nonclassical Platinum Antitumor Agents: Perspectives for Design and Development of New Drugs Complementary to Cisplatin. Cancer Invest. 1993;11(5):578-589.

19. Roat-Malone RM. Bioinorganic Chemistry: A Short Course. 2nd ed. New Jersey: John Wiley \& Sons; 2007. 19-20 p

20. Keppler BK, Friesen C, Moritz, HG, et al. Tumor-inhibiting bis( $\beta$ Diketonato) metal complexes. Budotitane, cis-diethoxybis(1phenylbutane-1,3-dionato)titanium(IV). Bioinorg Chem 2005;78:97-127.

21. Kostova I. Ruthenium Complexes as Anticancer Agents. Curr Med Chem. 2006;13(9):1085-1107.

22. Lentz F, Drescher A, Lindauer A, et al. Pharmacokinetics of a Nove Anticancer Ruthenium Complex (KP1019, FFC14A) in a Phase I DoseEscalation Study. Anticancer Drugs. 2009;20(2):97-103.

23. Sava G, Clerici K, Capozzi I, et al. Reduction of Lung metastasis by ImH[trans- RuCl4(DMSO)Im]: Mechanism of the Selective Action Investigated on Mouse Tumors. Anticancer Drugs. 1999;10(1):129138.

24. Bergamo A, Gagliardi R, Scarcia V, et al. In vitro cell cycle arrest in vivo action on solid metastasizing tumors, and host toxicity of the antimetastatic drug NAMI-A and cisplatin. J Pharmacol Exp Ther. 1999;289(1):559-564.
25. Zorzet S, Bergamo A, Cocchietto M, et al. Lack of in vitro Cytotoxicity, Associated to Increased G2-M Cell Fraction and Inhibition of Matrigel Invasion, May Predict In Vivo-Selective Antimetastasis Activity of Ruthenium Complexes. J Pharmacol Exp Ther. 2000;295(3):927-933.

26. Hartinger CG, Jakupec MA, Zorbas-Seifried S, et al. KP1019, A New Redox-Active Anticancer Agent - Preclinical Development and Results of a Clinical Phase I Study in Tumor Patients. Chem Biodivers. 2008;5(10):2140-2155.

27. Briand GG, Burford N. Bismuth Compounds and Preparations with Biological or Medicinal Relevance. Chem Rev. 1999;99(9):2601-2658.

28. Reglinski J. Chemistry of Arsenic, Antimony, and Bismuth. In: Norman NC editor. London: Blackie Academic \& Professional; 1998.

29. Felson DT, Anderson JJ, Meenan RF. The Comparative Efficacy and Toxicity of Second-Line Drugs in Rheumatoid Arthritis Results of Two Meta-analyses. Arth Rheumat. 1999;33(10):1449-1461.

30. Klinkhoff A. An Editorial is a Golden Opportunity. J Rheumat 2005;32(6):978-979.

31. Thomson AJ, Gray HB. Bio-inorganic Chemistry. Curr Opin Chem Biol. 1998;2(2):155-158.

32. Waldron KJ, Robinson NJ. How do Bacterial Cells Ensure that Metalloproteins Get the Correct Metal? Nature Rev Microbiol. 2009;71(1):25-35.

33. Glusker JP, Katz AK, Bock CW. Metal Ions in Biological Systems. Rigaku J. 1999;16(2):8-16.

34. Bock CW, Kaufman A, Glusker JP. Coordination of Water to Magnesium Cations. Inorg Chem. 1994;33(3):419-427.

35. Bock CW, Katz AK, Markham GD, et al. Manganese as a Replacement for Magnesium and Zinc: Functional Comparison of the Divalent Metal Ions. J Amer Chem Soc. 1999;121(32):7360-7372.

36. Katz AK, Glusker JP. Roles of Zinc and Magnesium Ions in Enzymes. Adv Mol Struct Res.1998;4:227-279.

37. Carrell HL, Glusker JP, Berger V. et al. X-ray Analysis of D-Xylose Isomerase at 1.9A: Native Enzyme in Complex with Substrate and with a Mechanism-designed Inactivator. Proc Natl Acad Sci USA. 1989:86(12):4440-4444.

38. Leung D, Abbenante G, Fairlie DP. Protease Inhibitors: Current Status and Future Prospects. J Med Chem. 2000;43(3):305-341.

39. Gupta SP. Quantitative Structure-Activity Relationship Studies on Zinc-Containing Metalloproteinase Inhibitors. Chem Rev. 2007;107(7):3042-3087.

40. Parkin G. Synthetic Analogues Relevant to the Structure and Function of Zinc Enzymes. Chem Rev. 2004;104(2):699-768.

41. Martin RB. Practical hardness scales for metal ion complexes. Inorg Chim Acta. 2002;339:27-33. 